\title{
LAW SCIENCES
}

\section{PURPOSE OF FORENSIC EXAMINATION IN CIVIL AND ECONOMIC PROCEEDINGS: PROBLEMS OF THEORY AND PRACTICE}

\section{Volodymyr Vasyliev ${ }^{1}$}

DOI: https://doi.org/10.30525/978-9934-588-84-6-11

Forensic examination is characterized by the presence of a certain procedural form, characterized by special preparation of materials for forensic examination, procedurally determined procedure for its appointment and conduct, carried out in compliance with special legal requirements set by procedural law. However, the current procedural procedure for the appointment of forensic examination in civil and commercial proceedings does not always allow to fully use all the potential possibilities of using this means of proof, when there is a practical need. Scholars pointing out the shortcomings of the legal regulation of the procedure for appointing forensic examinations by the current procedural legislation, as well as the practice of its application by general courts, note that the problem of ensuring an effective mechanism for appointing and conducting forensic examinations is of particular interest not only to scholars but also to lawyers.

Agreeing with this position, we emphasize that the above determines the relevance of this issue both in terms of improving procedural law and in terms of improving existing case law. In addition, in the context of the research, one of the leading issues is the appointment of expertise, as its correct solution depends on the timeliness and effectiveness of the use of special knowledge in the form of expertise in civil and commercial proceedings.

Analysis of the current civil and commercial procedural legislation allowed us to conclude that the statutory procedure for the appointment of a forensic examination involves addressing a number of key issues regarding: the grounds for the appointment of an examination; establishment of the subject of examination; determination of the range of

\footnotetext{
${ }^{1}$ Kharkiv Research Institute of Forensic Examinations of the Ministry of Justice of Ukraine, Ukraine
} 
questions of the expert; choice of expert; procedural registration of the appointment of examination, etc. Note that these issues are closely related and the general procedure for the appointment of the examination is impossible without resolving at least one of them. It is considered expedient to dwell on the features of some of them.

If one party applies to the court for an expert examination, the other has the right to object to it, as both parties have equal rights to present evidence and participate in the examination of evidence. It follows that in fact the legislator deprived the court of the power to initiate the appointment of an expert examination, securing this right for the parties, while leaving the court the discretion to rule on the request of the parties to conduct an examination.

When considering civil cases, the court must establish such facts, the data of which require special investigations. Such facts may include evidence of the nature of the person's illness or the nature and extent of the damage to health, or the removal of obstacles to land use. In this case, the court, deciding on the appropriateness of the appointment of an expert examination in a civil case or in resolving a commercial dispute, must take into account the following issues:

- first, whether the fact to be established by the expert is relevant to the case;

- secondly, whether it is not possible to prove this or that fact by other evidence gathered in the case;

- thirdly, what are the real possibilities of a forensic examination.

During the examination, the expert works with specific information that must be reliably established at the time of the study, in other words, be such that there is no doubt, ensures the reliability of the expert's opinion and its probative value. If these conditions are not met, the final result of the examination is likely to be plausible, which is unacceptable in terms of its role in the process of proof, as it does not allow it to be used as a means of proof.

The appointment of a forensic examination is a complex process that is the result of the exercise of both the powers of the court and the initiative of the persons involved in the case, and the courts have no right to ignore the position of the parties to the case. In addition, when deciding on the expediency of appointing an expert in a civil case or in resolving a commercial dispute, must take into account: whether the fact that the expert must establish is relevant to the case; whether it is not possible to prove this or that fact by other evidence gathered in the case; what are the 
real possibilities of a forensic examination that is its subject. In addition, the subject of the examination is proposed to recognize the circumstances that are relevant to the case and require timely establishment using the special knowledge of the expert in the relevant field of knowledge.

\section{SOCIAL RIGHTS IN PRACTICE OF THE EUROPEAN COURT OF HUMAN RIGHTS}

\section{Kateryna Denysenko ${ }^{1}$}

DOI: https://doi.org/10.30525/978-9934-588-84-6-12

Important tasks of the state in today's conditions are the following: incomplete process of democratization of Ukrainian society, searching for the optimal model of interaction of the state with socially vulnerable subjects, in particular those ones who have been exposed to social risk or are in difficult life circumstances, introduction of democratic standards and generally accepted European values, observance of rights, freedoms and guarantees of citizens who have experienced social risk or are in difficult life circumstances. Despite this fact, Ukraine's aspirations to join the European community as a full member are accompanied by the need to adjust national legislation in accordance with the norms of the European society, in particular in terms of observance and effective implementation of human and a citizen's social rights.

It is noteworthy that despite the significant development of modern science, there is still no generally accepted understanding of the category of «social rights». Thus, some scholars understand the concept of «social rights» as the ability of a person to realize their capabilities in order to ensure a decent standard of living and employment, as well as the ability to claim from the state certain material benefits [1, p. 40]. At the same time, others understand it as the rights to which a person has a direct right. This is expressed in the possibility of acquiring social benefits, their possessing, using and disposing as well as their protecting or taking certain actions in this area, as well as ensuring adequate social living conditions by guaranteeing and ensuring these rights by the state [2, p. 21].

\footnotetext{
${ }^{1}$ Academy of the State Penitentiary Service, Ukraine
} 